\title{
Chicken Meat, Beef and Vegetables: Potential Sources of Campylobacter jejuni Contamination in Imo State, Nigeria
}

\author{
Adeleye S.A. ${ }^{{ }^{*}}$, Braide W. ${ }^{1}$, Chinakwe E.C. ${ }^{1}$, Esonu C.E ${ }^{2}$. and Uzoh, C.V. ${ }^{3}$ \\ ${ }^{1}$ Department of Microbiology, Federal University of Technology P.M.B 1526 Owerri, Imo State, \\ Nigeria \\ ${ }^{2}$ Department of Biochemistry, Federal University of Technology P.M.B 1526 Owerri, Imo State, \\ Nigeria \\ ${ }^{3}$ Department of Microbiology, Federal University Ndufu-Alike Ikwo P.M.B 1010, Abakaliki, \\ Ebonyi State, Nigeria
}

*adeleye.adeniyi@futo.edu.ng, adeleyesamuela@gmail.com

Keywords: ABIS online, Campylobacter spp., Incidence, Meat, Vegetables.

\begin{abstract}
This work was carried out to determine the incidence of Campylobacter jejuni in selected food products in Imo state, Nigeria. Unprocessed chicken meat, beef and processed salad vegetables (diced carrots and cabbage) were assessed for the incidence of Campylobacter jejuni. 600 samples were collected between August, 2017 and December, 2017 from selected local markets. The Campylobacter jejuni was characterized using relevant biochemical test, growth characteristics and antimicrobial susceptibility and the results were read off using ABIS online showing $99 \%$ similarity with $65 \%$ accuracy. Results show that chicken samples isolated from Ihiagwa and relief markets were positive to Campylobacter jejuni with a $96 \%$ and $95 \%$ incidence respectively. More beef samples from Relief market were positive compared to those from Ihiagwa market with $56 \%$ and $43 \%$ incidence respectively. On the other hand higher incidence was reported for the salad vegetables from Relief market than those from Ihiagwa market with values of $22 \%$ and $16 \%$ respectively. Also most samples from Relief Market had higher microbial load than samples from Ihiagwa market. This work stresses the need for routine checks on meat sold in markets and also recommends proper processing of meat and vegetable samples before consumption.
\end{abstract}

\section{Introduction}

Food safety issues, portability and food availability are issues of concern globally [1]. On a daily basis, food production processes as well as food preservation techniques are employed in the food industry. However, the quality of food entering local markets needs to be checked. It is often true that food quality indicators could be physical (appearance, organoleptic, shape, etc.) or chemical (chemical oxidation, rancidity, etc.). However, determination of microbial quality requires special techniques as they cannot be determined through physical means. Indeed, food substances bearing organisms of public health concern may appear physically or chemically safe. Routine check of food products for microbial quality is therefore highly required. Campylobacter jejuni, the causative organism of a diarrheal disease often referred to as Campylobacteriosis, is a food borne zoonotic pathogen that has received global attention recently [1-3]. As a Zoonotic pathogen of global attention, infection in human arises as a result of consuming food substances which have been in contact with a reservoir of the pathogen or during handling of Poultry meats, offal or products as well as their exudates or faeces. [3]. This implies that there could be possible transmission of this pathogen through materials that come in contact with the faecal wastes or exudates of infected animals. Moreover, there is limited information about the vehicular transmission of these pathogens in red meat and vegetables. Recently, a study in Imo state Nigeria indicated some meat and meat products having high loads of C. jejuni [2]. Antimicrobial therapy is usually not required in some cases of Campylobacteriosis due to its self-limiting nature but in invasive cases of the disease and some cases of septicemia that is observed in immunocompromised 
patients observed as prolonged enteritis, antibacterial therapy may be needed. It has been reported that Macrolides (erythromycin) and quinolones, including fluoroquinolones (ciprofloxacin, nalidixic acid), are effective for treatment of cases of Campylobacter infections [4]. As a result, this work tends to present cases where Campylobacter jejuni was seen in Red meat and diced vegetables(carrots and cabbage); indicating a potential public health risk to poor food handlers.

\section{Materials and Method}

\section{Sample collection}

Uncooked beef, chicken meat and diced vegetable samples were obtained from two markets within Owerri zone which include Ihiagwa Market and Relief market. 100 samples each were collected from each location making a total of 600 samples. Each sample type was collected, appropriately labelled and transported immediately after to the laboratory for analysis.

\section{Sample preparation.}

The sample was prepared according to methods described in Braide et al. [2]. Each sample was blended in a sterile stomacher blender and emptied into a sterile container. A ten-fold serial dilution of the sample was done by measuring $10 \mathrm{~g}$ of the blended sample into $90 \mathrm{ml}$ of sterile water to produce a stock solution and an accompanied serial dilution up to the 5 diluent $\left(10^{-5}\right)$.

\section{Isolation of Campylobacter species from samples.}

$0.1 \mathrm{ml}$ of the fifth diluent was plated over the surface of a freshly prepared and surface dried Campylobacter Blood-Free Selective Agar Base (Modified CCD-Preston, Oxoid LTD, Basingstoke, Hampshire, England) using the spread plate technique. The inoculated plates were incubated at $37^{\circ} \mathrm{C}$ for 24 hours in a microaerophillic environment. Counts were obtained in colony forming units (CFU) per gram following incubation. Discrete colonies formed after incubation were subcultured onto the surface of a surface dried prospective medium as described in above. Pure cultures obtained were inoculated into $10 \mathrm{ml}$ of Tryptic Soy Broth and on the surface of Agar Slants for further use.

\section{Bacterial identification}

The identification was based on a biochemical test based international software available at http://www.tgw1916.net/bacteria_logare_desktop.html. Selected biochemical tests were conducted and the results were fed into the online software where the results were computed and displayed. Below are the set of tests required for the identification of the test isolates.

\section{Growth characteristics}

Ability to grow in basal media containing $2 \% \mathrm{NaCl}, 2 \% \mathrm{Bile}$, Nalidixic acid, NaF, Safranin, and growth at $25^{\circ} \mathrm{C}$ and $42^{\circ} \mathrm{C}$ were evaluated. Growth of the isolate on MacConkey agar was also done and all incubations were done at $37^{\circ} \mathrm{C}$ in microaerophilic environments for 48 hours.

\section{Nitrate Reduction Test}

A $24 \mathrm{~h}$ culture was added to three test tube of nitrate broth and incubated at $37^{\circ} \mathrm{C}$ for 48 hours. After incubation, the setup was tested for the presence of nitrate by adding dropperful of sulfanilic acid and 1 dropperful of alpha-naphthylamine reagent. The culture was shaken for a minute. Introduction of oxygen interferes with reduction. Postive test showed a distinct red colour (which may turn brown rapidly) appeared indicating $\mathrm{NO}_{3}$ has been reduced to $\mathrm{NO}_{2}$.

If no colour change occurred upon addition of zinc, this means that the nitrate has been reduced by the bacteria beyond the nitrate stage to $\mathrm{NH}_{3}$, or $\mathrm{N}_{2}$ hence the result was regarded as negative [5]. 


\section{Hydrogen sulphide $\left(\mathrm{H}_{2} \mathrm{~S}\right)$ production}

An aseptic stab innoculation of peptone iron agar tubes was made using inoculating needles. A comparative control was also set up at $37^{\circ} \mathrm{C}$ for 48 hours. The iron sulphide production was manifested as a black precipitate in the medium [5].

\section{Indoxyl acetate hydrolysis}

Disks were prepared in 10\% solution of indoxyl acetate in acetone. Fifty micro litres of the solution was added to each blank paper disc prepared from filter papers (diameter, $0.6 \mathrm{~cm}$ ). The discs were dried at room temperature and stored at $4^{\circ} \mathrm{C}$ in a brown tube containing a dessicant. The prepared filter papers were placed on a cultured plate containing suspected isolate and a drop of water was added. A positive reaction was indicated by an indigo colour formation within 10 minutes.

\section{Oxidase test}

A piece of filter paper was placed in a sterile Petri dish and flooded with oxidase reagent. A colony of the isolate was picked with sterile inoculating loop and smeared on the moistened filter paper containing oxidase reagent. A deep purple or violet color on filter paper within 10 seconds indicated a positive test.

\section{Urease test}

Each isolate was inoculated into a sterilized bijou bottle containing urease medium and incubated at $37^{\circ} \mathrm{C}$ for 24 hours. A positive result showed a change in colour from yellow to pink.

\section{Disk Diffusion Assay for sensitivity to Cefoperazone (60 $\mu \mathrm{g}$ disk) and Cephalotin (30 $\mu \mathrm{g}$ disk)}

The Kirby Bauer disk diffusion method was adopted, A bacterial suspension approximated to be 0.5 Macfarland's standard was inoculated onto the surface of a freshly prepared and surfaceddried Mueller-Hinton agar (MHA) plate ( $\mathrm{pH}$ 5.9) with a sterile cotton-tipped swab stick so as to obtain an even lawn. Sterile antibiotic disks (6 $\mathrm{mm}$ in diameter; BD 25 Diagnostic Systems) containing Cefoperazone (60 $\mu \mathrm{g}$ disk) and Cephalotin (30 $\mu \mathrm{g}$ disk) were placed on the surface of each inoculated MHA plate using a sterile pair of forceps. The plates were incubated in Microoerophillic conditions at $37^{\circ} \mathrm{C}$ for $48 \mathrm{~h}$. The diameter of inhibition zone was measured in millimeteres after $48 \mathrm{~h}$ incubation using a ruler.

\section{Alkaline phosphatase (PAL)}

To one $\mathrm{ml}$ of bacterial suspension taken in glass tubes, $4 \mathrm{ml}$ of modified universal buffer $\mathrm{pH}$ 11 (for assay of alkaline phosphatase) was added followed by addition of $1 \mathrm{ml}$ of 4-nitrophenyl solution. The glass tubes were swirled for few seconds to mix the contents, stoppered and incubated for one hour at $37 \pm 0.5^{\circ} \mathrm{C}$ in BOD incubator. To each of these tubes, one $\mathrm{ml}$ of $0.5 \mathrm{M} \mathrm{CaCl}_{2}$ was added followed by addition of $4 \mathrm{ml}$ of $0.5 \mathrm{M} \mathrm{NaOH}$ to deactivate the enzyme and to extract the 4nitrophenyl liberated. The glass tubes were swirled and the soil suspension was filtered through Whatman No. 42 filter paper. The absorbance of yellow color of 4-nitrophenol liberated due to hydrolysis of the substrate by phosphomonoesterases which was measured at $420 \mathrm{~nm}$ indicated positive results.

\section{Hippurate hydrolysis}

Rapid Hippurate Hydrolysis Method for Presumptive Identification of Group B Streptococci as described by Hwang and Ederer [6] was carried out using 1\% aqueous solution of sodium Hippurate (Nutritional Biochemical Corporation) coupled with a solution of $3.5 \mathrm{~g}$ Ninhydrin (Sigma Chemical Co., St. Louis, Missouri) per $100 \mathrm{ml}$ of a 1:1 mixture of acetone and butanol. The colour change was recorded at the end of a 3 min period rather than $10 \mathrm{~min}$. 


\section{Motility tests (hanging drop techniques)}

This test is used to ascertain motility of microorganisms. A drop of normal saline $(0.85 \%$ $\mathrm{NaCl}$ in distilled water) was placed on a glass slide, and a flamed wire loop was used to collect a colony from a 24 hours culture medium. This was dropped into the drop of water on the slide and covered with a cover slip. The slides of the slip firmly attached to the slide were smeared with petroleum jelly before it was previewed under a microscope.

\section{Gram staining}

Staining was done in order to classify bacterial species into either Gram positive or Gram negative. As well as distinguish cell morphology e.g. as either rod-shaped organism or coccus. The gram staining reagent included: crystal, violet, Iodine solution, Alcohol and Safranin.

In this procedure, an inoculating wire loop was flamed till it became red hot; it was then used to put a loopful of water on the slide. It was flamed again and allowed to cool slightly before a loopful of culture was collected, smeared on the slide and air dried; later the smear was heat-fixed by quickly passing the slide through a flame, 3 times. Then the actual gram staining was done by flooding the slide with crystal violet and allowing to react for a minute before rinsing with water; followed by the Gram's iodine which was also left for 1 minute before being washed off with alcohol (ethanol) and finally rinsed with water. A few drops of safranin was added and left to react for 15 seconds before rinsing off with water. The slide was air dried and viewed under a microscope. Gram positive organisms picked up the primary dye (purple) while the gram negative organisms picked up the secondary stain and were stained red.

\section{Results}

\section{Characterization of Campylobacter jejuni}

The pure culture of Campylobacter jejuni is shown in Fig. 1. Campylobacter jejuni appeared as white colonies over a dark charcoal background of the Campy medium. On the other hand, the characterization of Campylobacter jejuni following guideline from ABIS online is displayed in Table 1. The colonies isolated were white mucoid colonies which were motile gram negative curved rods. The isolates were characterized based on their enzyme activity, Growth characteristics and sensitivity to antibiotics. Results show that Campylobacter jejuni has the ability to hydrolyse hippurate and is also positive to oxidase and alkaline phosphatases. The selected isolates also tested negative to other parameters tested as shown in Table 1. Results produced by ABIS online is shown in Fig. 2. Results shows that the characterized colonies were $99 \%$ related to the target isolate (Campylobacter jejuni) with about 65\% accuracy.

\section{Incidence and Microbial Load of meat and vegetable samples}

Results obtained from individual counts indicated that all positively tested samples had counts that were above the infective dose of $500 \mathrm{Cfu} / \mathrm{ml}$. Results were summarized logarithmic values of the counts in Figs. 3 and 4. Results of the incidence data is shown in Fig. 4. Results show that chicken samples isolated from Ihiagwa and relief markets were positive to Campylobacter jejuni with a $96 \%$ and $95 \%$ incidence. More samples of beef were from Relief market were positive compared to those from Ihiagwa market with $56 \%$ and $43 \%$ incidence respectively. On the other hand higher incidence was reported for vegetables from Relief market than those from Ihiagwa market with values of $22 \%$ and $16 \%$ respectively. Results concludes higher incidence of the isolates from Chicken meat than beef meat and also Beef meat than vegetables. The decreased trend in $C$. jejuni incidence can be represented as

\section{Chicken meat $>$ Beef Meat $>$ Vegetables}

Fig. 3 shows the average counts of the isolates obtained from the markets. Results show that despite the similar incidence data on chicken meat, samples from Relief Market had higher microbial load. Also all samples from Relief Market had higher microbial load than samples from Ihiagwa market. 
Table 1: Characterization of Campylobacter jejuni using ABIS online software.

\begin{tabular}{ll}
\hline \multicolumn{2}{c}{ Enzyme assays } \\
\hline Indoxyl hydrolysis & Negative \\
Urease & Negative \\
Hippurate & Positive \\
hydrolysis & \\
Oxidase & Positive \\
Nitrates & Negative \\
Selenite & Negative \\
$\mathrm{H}_{2} \mathrm{~S}$ & Negative \\
PAL & Positive \\
\hline \multicolumn{2}{c}{ Cultural assay } \\
\hline Growth at $25^{\circ} \mathrm{C}$ & negative \\
Growth at $42^{\circ} \mathrm{C}$ & negative \\
$2 \%$ NaCl & Negative \\
Nalidixic acid & Negative \\
NaF & Negative \\
Safranin & Negative \\
MacConkey & Negative \\
\hline \multicolumn{2}{c}{ Susceptibility testing } \\
\hline Cefoperazone & Negative \\
Cephalotin & Negative \\
\hline
\end{tabular}

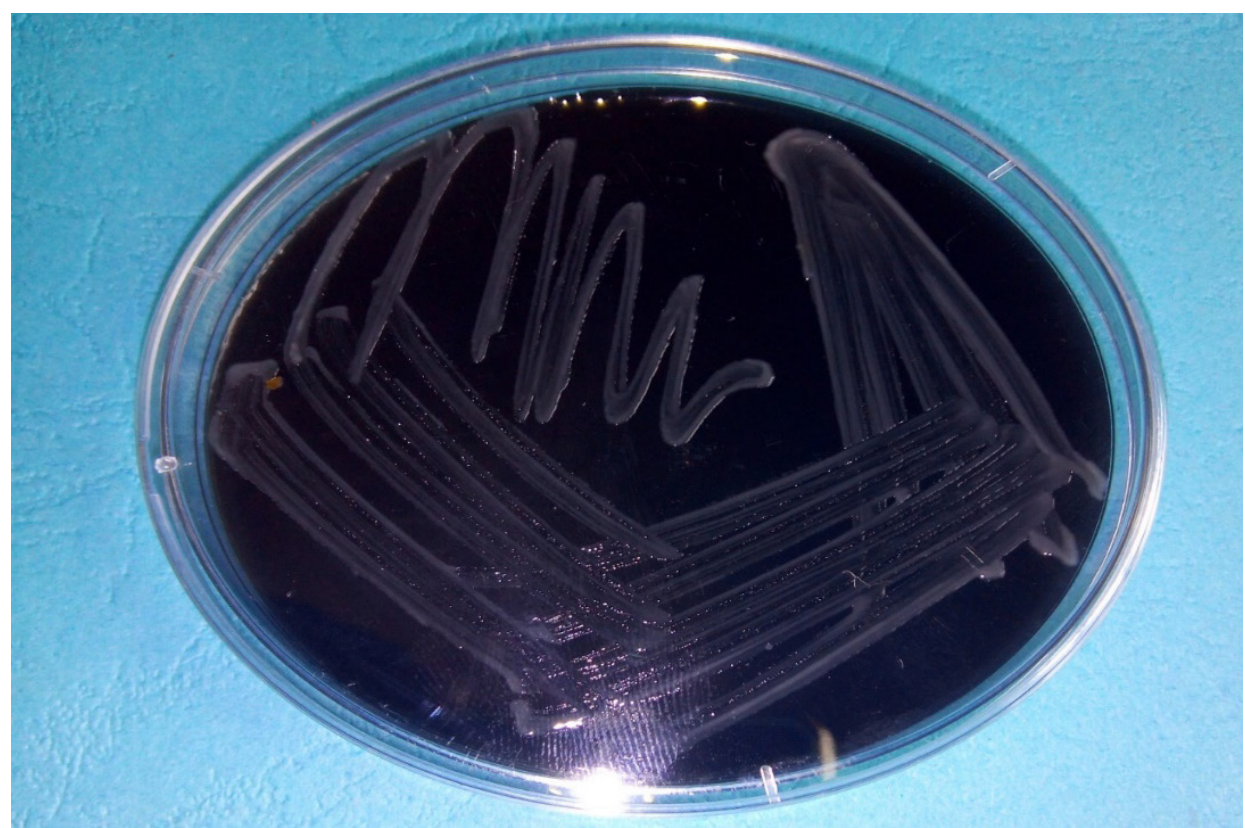

Figure 1: Campylobacter jejuni on Charcoal black campy Agar. 


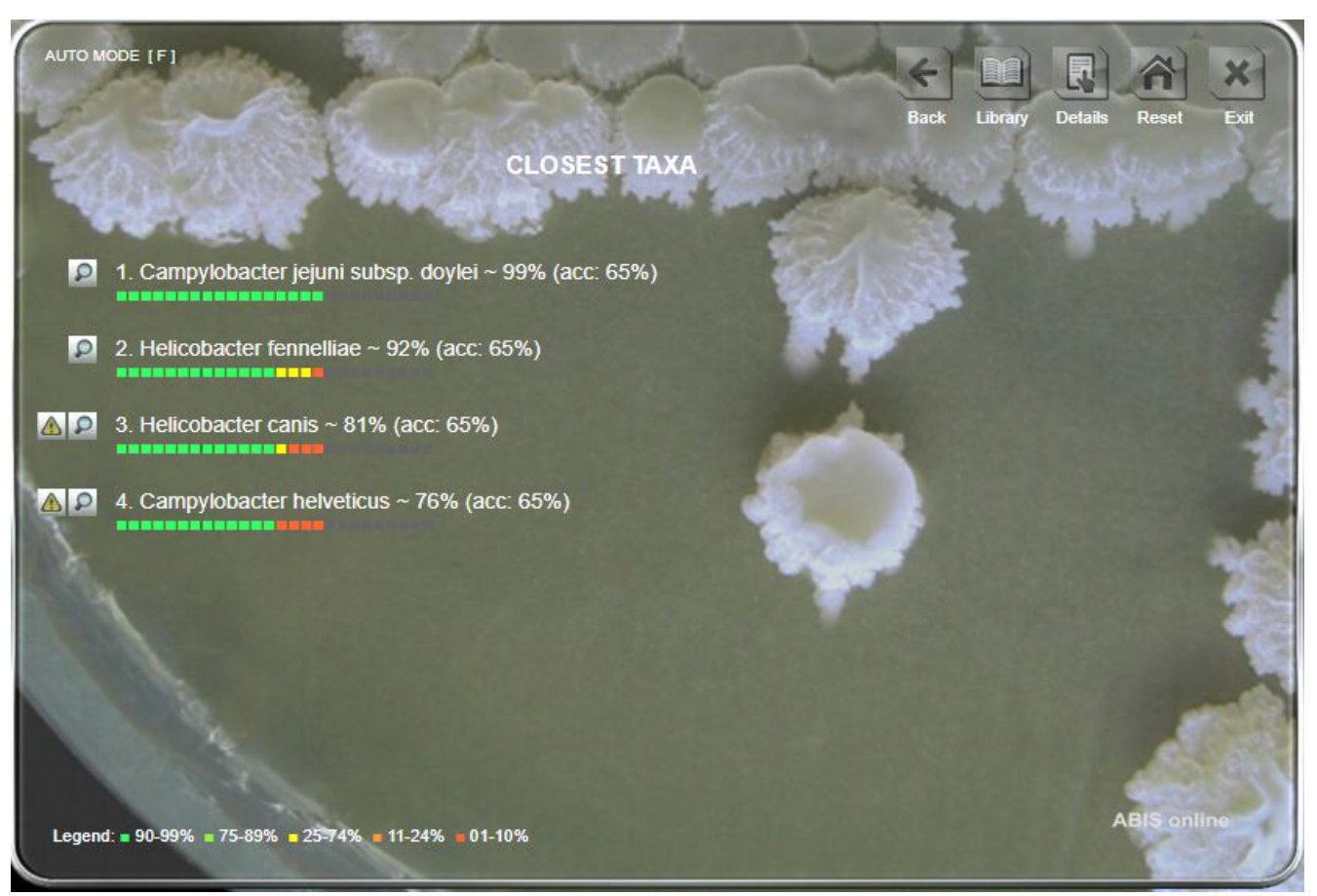

Figure 2: ABIS Online results for Campylobacter jejuni Identification.

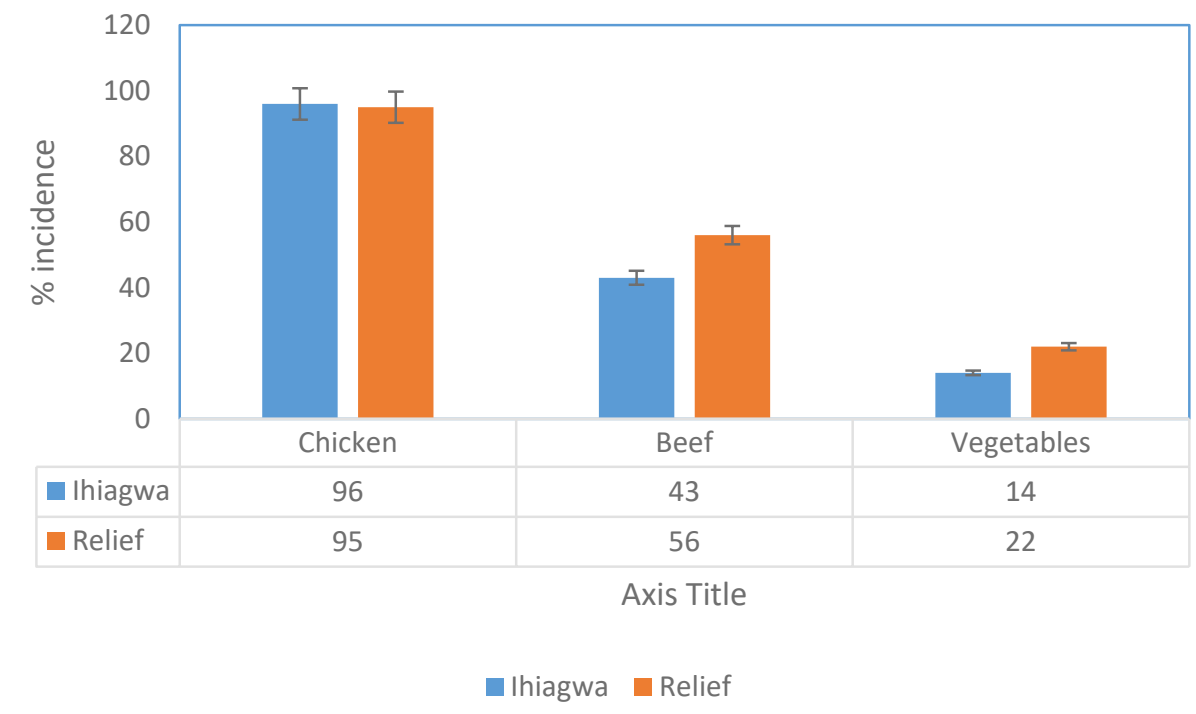

Figure 3. Incidence of Campylobacter jejuni from meat and vegetable samples. 


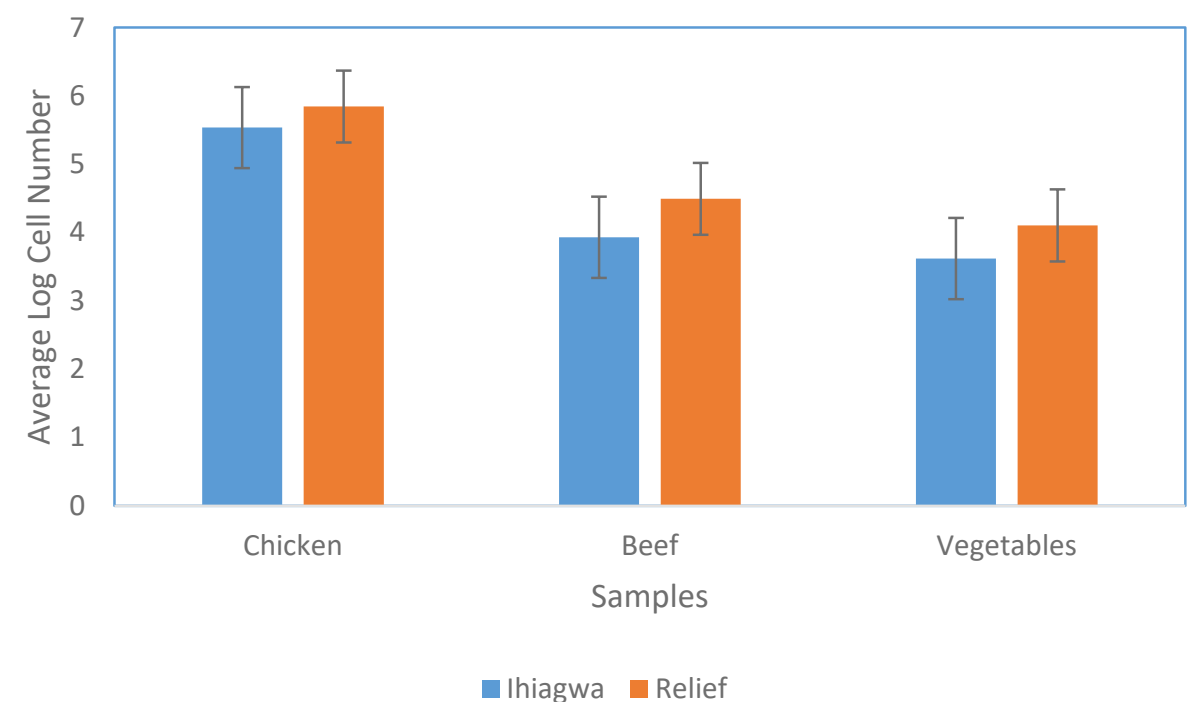

Figure 4. Microbial load of samples obtained from Relief and Ihiagwa Market.

\section{Discussion}

Principally, Campylobacter jejuni, the leading cause of Campylobacteriosis, is identified to be of poultry origin and thus is ascribed as the primary reservoir. Indeed, studies have shown that consumption or handling of raw or poorly processed chicken is a cogent risk factor for Campylobacteriosis in humans. [7-9]. Different studies in different countries shows varying statistics on the faction of Human Campylobacteriosis cases arising from the consumption of poultry after poor handling and unhygienic processing. For instance, estimates of cases of foodborne origin was reportedly within the $30 \%$ [10] 2006) to $58 \%-76 \%$ [9] range. In addition, up to $80 \%$ of such cases are attributed to the chicken reservoir as a whole [7].

In this research, meat and vegetable samples were analyzed to obtain the levels of risk associated with direct consumption of the samples. This can also have implication for food handlers in food processing industries. The result revealed different levels of contamination of the meat and vegetable samples sold in the different markets used in this study. For instance, an incidence of 1496\% Campylobacter jejuni was observed on the analyzed samples with chicken meat having the greatest incidence.

This research shows that the presence of Campylobacter spp. in the meat samples and vegetables are evident. Muller et al. [9] previously ascribed meat handlers and food processing methods as the primary source of contamination. The high incidence of Campylobacter spp. in the meat and vegetable sample may suggest that there is a unified meat vendor or rather a similitude in the Manufacturing practices. In addition, methods adopted in transport and further processing may result in the differences in the Microbial load recorded [8]. As these slaughterhouses are processing the meat samples, run off water may transport the isolate into water bodies which can be used for irrigation of vegetables. This implies that contamination of water and cross contamination of vegetables are possible. These have an implication of spreading the isolates to secondary reservoirs. Previous Studies indicated that a 3 days exposure of a poultry flock to a single Campylobacter spp. infected bird is enough to cause colonization of majority of the flock [11]. This is possible because contact with contaminated water, poultry litter, faecal matter and other exudates as well as other vectors such as insects [12], rodents and farm personnel [13] are sufficient for horizontal transmission.

When these infected poultry enters the processing plant, they have a Campylobacter spp. populations within the range of $10^{5}$ to $10^{8} \mathrm{CFU} / \mathrm{g}$ of faeces. This high levels of the organism allow the bacteria to proliferate, dominate and easily spread throughout the plant [14]. The scalding and defeathering procedures have the potential for cross-contamination. Campylobacter spp. has periodically been removed from scald water and it has been postulated that the opening and closing 
of follicles may allow the retention of Campylobacter spp. within the carcass [14]. The use of recycled water and mechanical parts of the processing plants are other procedures that give rise to cross contamination. Campylobacter spp. may also be transported throughout a processing plant by personnel moving from one area of the plant to another [14].

Beef and vegetables harboring $C$. jejuni is an indication of cross contamination. Raw beef as well as poorly processed vegetables had previously reported as sources of foodborne Campylobacteriosis in humans $[15,16]$. Campylobacter spp. have also been isolated from milk arising from faecal contamination during the milking process or an udder infection [16]. A recent study from the United States found that 5\% (12/262) of Campylobacteriosis outbreaks from 19972008 were due to consumption of contaminated pork, beef or game [17]. These indicates that there could be other environmental reservoirs of this isolate other than poultry.

\section{Conclusion and Recommendation}

Due to the numerous opportunities for cross contamination, meat processing plants and retailers should employ a variety of decontamination or contamination reducing techniques such as physical, chemical and irradiation based treatments $[14,18]$. These treatments play major roles in significantly reducing the levels of Campylobacter spp., but are unable to achieve complete removal since dose levels as low as 500 organisms have been reported to cause illness and the contaminated carcasses can still pose a threat to public health [14]. Contaminated poultry can also result in cross contamination to other reservoirs, including food produce [18] and natural waters [19]. This work has demonstrated that Vehicular agents for the transmission of Campylobacter jejuni, the leading cause of Campylobacteriosis is present in Owerri, Imo state's Markets. Probable source of contamination could result from the fact that the vendors obtained the meat samples from same network of supplier. The differences in handling the meat samples from the point of purchase to the point of vendor could attribute to the differences in load. Campylobacter spp. have also been reported to be heat labile and is destroyed by proper cooking. Therefore, the need for proper meat handling from the slaughter house to the vendor is highly recommended.

Campylobacter spp. have been associated mainly with birds; but this research has shown that there is a possible source of infection from beef. Best cooking practices and good production practices can be the best means of avoiding infections from Campylobacter jejuni.

\section{Conflict of Interest}

The authors declare that there is no conflict of interest.

\section{References}

[1]. WHO, The Global View of Campylobacteriosis: report of an expert consultation. World health organization, document production services, Geneva, Switzerland, 2013.

[2]. W. Braide et al., Incidence of Camplylobacter species in poultry products and beef sold in Owerri, Imo State, Nigeria, EC Microbiology. 10(4) (2017) 147-15.

[3]. H.F. Fernandez, Campylobacter y Campylobacterioosis: Una Mirada desdedelsur (Campylobacter and Campylobacteriosis: A view from South America), Revistaperuana de medicina experimental y SaludPublica. 28 (2011)121-127.

[4]. K. Wieczorek, R. Szewczyk, J. Osek, Prevalence, antimicrobial resistance, and molecular characterization of Campylobacter jejuni and C. coli isolated from retail raw meat in Poland, Veterinarni Medicina. 57(6) (2012) 293-299

[5]. L. Beishir, Microbiology in Practice, $6^{\text {th }}$ edition, Pearson Publishers, 1996.

[6]. M.-N. Hwang, G.M. Ederer, Rapid hippurate hydrolysis method for presumptive identification of group B streptococci, Journal of Clinical Microbiology. 1(1) (1975) 114-115. 
[7]. G.L. Mughini et al., Risk factors for Campylobacteriosis of chicken, ruminant, and environmental origin: A combined case-control and source attribution analysis, PLoSOne. 7 (2012) e42599.

[8]. D.G. Newell et al., Changes in the carriage of Campylobacter strains by poultry carcasses during processing in abattoirs, Appl. Environ. Microbiol. 67 (2001) 2636-2640.

[9]. P. Mullner et al., Assigning the source of human Campylobacteriosis in New Zealand: A comparative genetic and epidemiological approach, Infect. Genet. Evol. 9 (2009) 1311-1319.

[10]. A.P. Black, M.D. Kirk, G. Millard, Campylobacter outbreak due to chicken consumption at an Australian Capital Territory restaurant, CDI. 30 (2006) 373-377.

[11]. S. Shanker, A. Lee, T.C. Sorrell, Horizontal transmission of Campylobacter jejuni amongst broiler chicks: Experimental studies, Epidemiol. Infect. 104 (1990) 101-110.

[12]. G.L. Nichols, Fly transmission of Campylobacter, Emerg. Infect. Dis. 11 (2005) 361-364.

[13]. N.J. Stern et al., Distribution of Campylobacter spp. In selected U.S. Poultry production and processing operations, J. Food Prot. 64 (2001). 1705-1710.

[14]. K.M. Keener et al., Comprehensive review of Campylobacter and poultry processing, Compr. Review Food Science and Food Safety. 4 (2004) 105-116.

[15]. L. Verhoeff-Bakkenes et al., Consumption of raw vegetables and fruits: a risk factor for Campylobacter infections, Int. J. Food Microbiol. 144(3) (2011) 406-412.

[16]. R. Delphine et al., Differences in the fecal concentration and genetic diversity of Campylobacter jejuni populations among individual cows in two dairy herds, Applied and Environmental Microbiology. 78(21) (2012) 7564-7571.

[17]. E.V. Taylor et al., Common source outbreaks of Campylobacter infection in the USA, 19972008, Epidemiol. Infect. 141(5) (2013) 987-996.

[18]. M.B. Peyrat et al., Recovery of Campylobacter jejuni from surfaces of poultry slaughterhouses after cleaning and disinfection procedures: Analysis of a potential source of carcass contamination, Int. J. Food Microbiol. 124 (2008) 188-194.

[19]. E. Jr. Vereen et al., Distribution and ecology of Campylobacter in coastal plain streams (Georgia, United States of America), Appl. Environ. Microbiol. 73 (2007) 1395-1403. 